\title{
Politics-as-exchange and The Calculus of Consent
}

\author{
Geoffrey Brennan
}

(c) Springer Science+Business Media, LLC 2012

\section{Introduction}

Buchanan has always insisted that a central element in the broad "public choice" project, of which The Calculus of Consent is perhaps the classic exemplar, is the idea of "politics as exchange" [PAE henceforth]. In this piece, I want to explore what exactly this PAE conception might amount to. In other words, my object here is to "go back to basics" in a way that Buchanan himself so often did. Much of my treatment here will abstract from the details of the argument in the Calculus. However, I shall at the end offer a conjecture as to how these more general considerations might be brought to bear directly on the analysis of "optimal" collective-decision rules - an analysis that is perhaps the single most familiar piece of the Calculus apparatus.

\section{PAE-compared to what?}

It will help to get a fix on what is at stake in the PAE idea to ask what the PAE-approach stands in contrast to. Buchanan has in mind, I think, three specific contrasts-three alternative approaches-which the PAE approach explicitly opposes:

2.1 Politics as the "quest for the true and/or the beautiful"

PAE rules out those accounts that interpret and assess political processes directly in terms of external normative criteria. For such purposes, the term "external" is to be understood

\footnotetext{
G. Brennan $(\bowtie)$

Australian National University, Canberra, Australia

e-mail: geoffrey.brennan@anu.edu.au

G. Brennan

Duke University, UNC, Chapel Hill, NC, USA
} 
in terms of criteria that operate independently of the values/preferences of the individual citizens who compose the polity. There may be shades of grey involved here to the extent that the agents' "values" diverge from their "preferences" because in that case the criteria of assessment stand at arms length from the behavior (and/or resultant social outcomes) to be assessed-and do so even from an individual standpoint. Notwithstanding such possible complications, the political process is to be analyzed and evaluated from a reference-point that is in some way grounded in expressed individual preferences.

\subsection{Politics as purely distributive}

I take it that, whatever else, the PAE perspective sees politics as an essentially non-zero-sum activity. Though political processes may have distributive aspects, to characterize political processes in terms of who gets what from whom tends to background the possibility that all may benefit (if indeed it does not overlook—or even deny—-that possibility altogether) or, more or less equivalently, that all may lose. ${ }^{1}$ Indeed, there is perhaps a suggestion in Buchanan's treatment that a preoccupation with distributional considerations may make it more likely that all may be less well off than otherwise - as if a focus on the positive-sum aspects of political process may exercise some influence on the process itself. ${ }^{2}$

\subsection{Economics as a study of constrained optimization}

Whether an "economic theory of politics" necessarily implies a PAE approach depends on how the underlying economic method is understood. Buchanan has always been a strong proponent of a conception of "economics as exchange." He used to say that the characteristic feature of a good course in Economic Principles is that it begins with exchange (and not, say, consumer rationality or even demand/supply analytics). He thought that Richard Whateley was right to claim that "economics" is a misleading term for the discipline-precisely because it smacks too much of 'household management' - and that "catallactics/catallaxy" is strongly to be preferred. This aspect of the PAE mindset is interesting both from the viewpoint of the authorship of the Calculus and more broadly within the public choice community, because it is not entirely clear that these are views that Tullock shares. ${ }^{3}$ And in this respect, Tullock is perhaps more broadly representative of the public choice mainstream. PAE could therefore be interpreted as a challenge to that mainstream.

\footnotetext{
${ }^{1}$ If all may lose, then all may win by not doing the something that creates those losses.

${ }^{2}$ This kind of Heisenbergian thought is explicit in a few places-for example in our Virginia Law Review piece where the question as to whether the public choice approach might be "immoral" because it moderates the force of norms (and public expectations) on political agents is seriously entertained (Brennan and Buchanan 1988).

${ }^{3}$ Tullock nowhere exhibits the same sympathy with the Austrian tradition that Buchanan does (in Cost and Choice most notably perhaps). It is not my intention here to elaborate the methodological differences, as I see them. Here, however, is how Buchanan himself saw it: "my debt to Gordon Tullock stems in part from his long-continuing insistence on the economic view of man, which has served to check my own tendencies to wander off into ethical and moral discourse. On the other hand and by contrast I think that my own continuing reluctance to view man, always and everywhere, as self-seeking explains my search for ways and means of reconciling self-interest with broader norms for social interaction. Appreciation of the essential tension between these two perspectives provides, I think, some understanding of the success of our major joint effort, The Calculus of Consent" (Buchanan 1987: 96f.).
} 


\section{PAE and its intellectual forebears}

There are two important traditions out of which The Calculus of Consent and its PAE aspects grow. One, perhaps the more obvious, is the "voluntary exchange" tradition in public finance, represented by Buchanan's hero, Knut Wicksell (1896/1958), and Wicksell's other notable follower, Erik Lindahl (1919/1958). To use the dichotomy developed by Buchanan in The Limits of Liberty (more than a decade after the Calculus) these voluntary exchange proponents focused on the activities of the "productive state" (as distinct from the "protective state") and on the possible gains from exchange on offer via the provision of public goods. As is well-known, the specific objective in the Calculus is to provide an analysis of alternative collective decision-making rules (of which simple majority rule is merely one instance) with an eye toward the extent to which different rules would maximize the expected net benefits from public goods provision. ${ }^{4}$ It is worth noting that, whereas the "calculus" that citizens are conceived to undertake involves maximizing net expected benefits (the net gains from exchange in public goods provision) - and in that sense presents itself as an exercise in constitutional "efficiency"- -both Wicksell and Lindahl present their contributions in terms of an account of the requirements of "justice". I shall return to that difference in the discussion that follows.

The other tradition in which the Calculus stands is the 'social contract' tradition in political philosophy. Here, too, a point of departure is the idea that politics, broadly construed, is a positive-sum activity. If there were not mutual benefits on offer, then would-be contractors engaged in the leap out of anarchy could not rationally contract! Although more evident in the Limits - and perhaps in relation to the "protective state" rather than the "productive state"- the social contract tradition nevertheless hovers in the background of the Calculus project. However, there is one aspect of that tradition from which Buchanan seeks to distance the Calculus exercise. Too much of the 'social contract' tradition is, in Buchanan's view, associated with the derivation of political obligation-something which (at least for the task set in the Calculus ${ }^{5}$ ) Buchanan sees as having little relevance. So, while the role of "Consent" is an explicit core piece of the Calculus project, it is not the obligation-creating properties of consent that are central: consent for Buchanan does somewhat different, independent work.

\section{4 "Economics, the science of markets or of exchange institutions"6}

If politics is appropriately to be analyzed in PAE terms, then politics is an exchange institution. But what exactly is meant by exchange? On what aspects of the process of exchange are we supposed to focus? If "exchange institutions" include but are not exhausted by markets, what role is played by specifically market exchange in framing the political analogue? I think it important here to isolate two possible lines in answering these questions; and to emphasize the differences between them.

\footnotetext{
${ }^{4}$ It is an explicit implication of their treatment that in the absence of any market failure at all-indeed, unless the degree of market failure exceeds the total of decision-making costs and external costs under the optimal decision rule-no case for government action is warranted.

${ }^{5}$ As Giuseppe Eusepi and I have argued elsewhere, the contrast in this respect with the Limits is very striking. Though Spinoza appears as the hero in the Calculus Appendix, and Hobbes as a second-order figure, by the time the Limits appears, Hobbes assumes center-stage: in the later book, Hobbes gets 13 references, Spinoza a mere two!

${ }^{6}$ The quote is taken from Buchanan (1975a: 24).
} 


\subsection{Exchange and rights}

The first is what I shall call a Nozickean answer. It takes, as its benchmark, the case of ordinary market exchange and focuses on the fact that the parties to any such exchange act voluntarily within the context of the given rules of market relations. Those rules include specifically norms against "force and fraud"-with "force" understood in terms of obedience to the prevailing rights structure and "fraud" interpreted with reference to actions that parties might take to mislead trading partners concerning relevant properties of the objects of exchange (or actions that parties might refrain from taking which, if taken, would disabuse the other of misapprehensions the other might harbor). On this Nozickean conception, it is the fact of consent among contracting parties that is crucial: market exchange thus becomes an instantiation of consensual interaction.

Interestingly, both Wicksell and Lindahl make much of this aspect. Wicksell's conception of "justice in taxation" involves (virtually) unanimous agreement, based on an "initially just" property rights distribution. And as Lindahl puts it in defending his "positive solution" to the problem of securing justice in taxation, the relevant "equilibrium position corresponds to a situation in which both parties have equally safeguarded the economic rights to which they are entitled under the existing property order" (Lindahl 1919/1958: 172). He later repeats the point: "It follows that in the field of taxation both parties will have equally safeguarded their interests... only at the standard equilibrium position which we have defined above" (1919/1958: 173).

I think it plausible to describe this conception of the PAE approach as libertarian in the sense that the central feature of market exchange (and its political analogue) is the absence of coercion. To be sure, as Wicksell in particular insists, the normative credentials of the outcome of exchange depend on the existing property order being "just."7 But one way of putting the Wicksell/Lindahl claim is that justice is not exhausted by the features of that prior property order-justice requires something more, namely that the political interactions that take place in the context of that property order be essentially non-coercive.

\subsection{Exchange and the gains from exchange}

The second possible focus in interpreting exchange within the PAE setting involves less the case of individual exchange and more attention to the properties of the "system" as a whole - the outcomes emergent from the entire trading nexus. In the standard welfare economics framework, this approach is articulated in familiar claims about the Pareto optimality of competitive market outcomes under certain well-known conditions. In the somewhat different proto-utilitarian picture offered by Adam Smith in the first few chapters of The Wealth of Nations, the central element in the market's capacity to create "a general plenty" that "diffuses itself through all the different ranks of the society" (Smith 1776/1981: 22) lies in the increasing returns associated with the division of labor. Market exchange in the Smithian picture is relevant primarily because it enables that division of labor to take place. In that sense, one might say that Smith's picture is technological rather than more narrowly catallactic. $^{8}$

\footnotetext{
${ }^{7}$ Both Wicksell (1896/1958: 108-116) and Lindahl (1919/1958: 173, fn. 4) are totally explicit on this point.

${ }^{8}$ The contrast between Smith's "increasing returns" picture and the conventional Arrow-Debreu-Ricardian picture is a feature of Buchanan's later writings (for example, Buchanan and Yoon 1994), but plays no role in the arguments of the Calculus.
} 
Whether the picture of market operation is specifically Smithian in this sense or not, what is notable within this, more systemic, view of the market order is that there can be no presumption that any specific transaction is fully "voluntary" in the sense that none of those who are affected by it suffer losses. Any given exchange presumably benefits those who are the exchanging parties - but the effects of that exchange include losses (as well as gains) endured by third and fourth, etc. parties. The market is a system of interdependence that connects each agent within the trading nexus to every other; and it is self-evident that "moves" within the market order serve to inflict losses on some parties. When I set up my hamburger stand next to yours in the market square I reduce your profits. When the "men of speculation" in the Smithian division of labor invent a new machine for the sharpening of pins they impose losses on those workers who have developed the relevant distinctive skills in the pin factory. Market "rights" certainly involve protections against certain kinds of losses that might be inflicted: but they also involve permissions to inflict losses of certain other kinds. As I say, I take this fact to be self-evident. So it is surprising that so many commentators (especially those who self-define as centrally concerned with "liberty") seem to regard market transactions as if they involved a partition of interdependence into simple bilateral relations. It takes two persons (at least) to make a voluntary exchange; but there is nothing about the exchange process that restricts the set of affected persons to those contracting parties.

We have of course good reason for thinking that, under appropriate circumstances, the aggregate effect of all these transactions does lead to a "general plenty" across "all ranks of society". We might even presume that in any individual transaction the aggregate of benefits to affected parties exceeds the aggregate of losses. ${ }^{9}$ But the "gains-from-exchange" are aggregated in both cases-either across all transactions or across all affected persons in a single transaction. And it is the aggregation of such gains across the entire trading nexus rather than the 'voluntariness' of each component that is the basis of normative endorsement. As I think becomes clear in the "constitutional political economy" program (as it evolves in Buchanan's works through the Calculus and the Limits and on perhaps to The Reason of Rules) the normative status of the market order within that scheme lies in the credentials of that order as an object of voluntary (constitutional) choice as much as an instantiation of voluntariness in each particular instance. ${ }^{10}$

Those who lose from any exchange undertaken by others do so involuntarily: that much seems clear. Such losses are not rights violations, and so they do not perhaps deserve the status of the term "harms". But that is so because of the normativity of the property rights structure. It is not a feature of the inbuilt distributive consequences of individual market transactions.

The "gains-from-exchange" associated with the market are the gains accruing from the market system as a whole. Over the long haul, and across the host of exchanges that occur at any one time, almost everyone can reasonably expect to benefit - and on average, they will benefit handsomely. But it is this consequentialist consideration that is the concern of the

\footnotetext{
${ }^{9}$ We might do this, for example, by distinguishing between pecuniary and technological externalities and stipulating that only the latter can be Pareto-relevant-but once one allows for transaction costs across large aggregations of interests, whether an 'externality' is pecuniary or technological becomes an analytical rather than an empirical category.

${ }^{10}$ In this sense, the question of whether and in what sense individuals do endorse the 'constitution of the market' becomes a central normative issue — and not a straightforward one. As Hume famously insists, constitutions are not, as a matter of fact, explicitly endorsed by those who are subject to them: no individual exercises an effective veto over the rules of the market order.
} 
PAE approach so construed. The work that exchange does is less to instantiate voluntariness, less to derive political obligation from the fact of consent, and more to create a framework within which the generalized gains from exchange on offer can be appropriated.

\section{From markets to politics}

Against this background, there seem to be three implications that emerge more or less directly:

\section{1 "Market rights" versus "political rights"}

It should be clear that within the Wicksell/Lindahl scheme, the political process involves a protection of the "rights assigned under the existing property order" that goes beyond anything that the market itself provides. Under quasi-unanimity, each agent has a quasiveto against losses-something which allows each to "safeguard interests" against any and all actions that might run contrary to those interests. Market rights allow the possessor to impose losses: political rights within the Wicksellian version of the "voluntary exchange" framework do not.

\subsection{Are market and political processes under majority rule equally non-coercive?}

It is of course a characteristic feature of the Buchanan/Tullock scheme that Wicksellian unanimity is "self-effacing", in the sense that individuals will rationally retreat from unanimity to a less restrictive decision-rule in order to appropriate gains-from-exchange in relation to public goods supply. The rational "calculus" of each will settle on an 'optimal' decision-rule that trades off the expected costs of decision-making against the expected net losses from decisions that will sometimes go against you. Under this modified (quasi-unanimously agreed) rule for collective decisions, you will sometimes lose under political 'exchanges' exactly as you do under market ones: you will sometimes be a member of the 'exploitable' minority and will sometimes sustain losses thereby. But this is just the price you pay for the overall benefits that the productive state provides-and by construction in the Buchanan/Tullock scheme, that is a price you pay "voluntarily" in the constitutional contractarian sense. In other words, markets and politics under an optimal decision-rule have equivalent normative status! Or at least, that is so, I think, if normative status is exhausted by aggregate gains from exchange. Whether it remains so under a more self-consciously 'rights-oriented' view of exchange I shall be concerned to explore below.

\subsection{Separation between in-period and constitutional politics}

Wicksell emphasizes that the 'voluntary exchange' mechanism he endorses operates on the basis of an already determined "just" property order. The analysis in the Calculus is conducted in the same spirit: “. . the science of ... exchange institutions, begins with a welldefined structure of individual rights ...” (Buchanan 1975a: 24). The retreat from unanimity in the Calculus follows Wicksell in observing a distinction between constitutional and inperiod politics: unanimity remains the appropriate rule for the former. ${ }^{11}$ Collective decisions

\footnotetext{
${ }^{11}$ It does so not, I think, because it is chosen as such but because that represents the contractarian foundation of the whole exercise. If everyone wished to depart from unanimity at the constitutional level, it is not entirely clear what Buchanan would say about that prospect—or more particularly what his position would oblige him to say. I take it that one option would be to respond that strict constitutional consensus is the normative core of the constitutional contractarian.
} 
about public goods provision have to be distinguished then from changes in the underlying property order that might be pursued through political process. Buchanan/Tullock make it clear (Chap. 13) that their analysis extends to income redistribution through the fisc to some extent - though they also emphasize that more restrictive decision rules are appropriate for issues that bear specifically on rights. Using the categories of the Calculus, collective decisions might properly be described as "coercive" if they involve the application of an inappropriately unrestrictive decision-rule —one that is less restrictive than the implications for the property rights structure would demand. Not everything that majorities do will, on that reasoning, be coercive: there does not seem to be any generalized support here for extreme libertarian positions (such as the blanket claim that "taxation is theft"). There do not seem to be grounds either for rejecting (some, perhaps extensive) redistribution from rich to poor via a welfare state ${ }^{12}$ - and, indeed, nor can we entirely reject the possibility of constitutionally legitimate redistribution from poor to rich, if the rich happen to constitute the relevant majority. The issue of precisely where the divide between 'constitutional' and in-period political jurisdictions should lie_-and what decision-rules should be relevant to which domains-is obviously critical here. But what I want to emphasize is that where the relevant lines ought to be drawn seems to depend to some extent on whether the PAE approach focuses on generalized gains from exchange or on the notions of 'voluntariness'/non-coercion that market exchange often is characterized as embodying. As we might put it, it depends on whether one takes a Nozickean or a Smithian view of markets.

\section{Decision-making versus external costs}

So far, what I have said has been at some distance from the analytic details in the Calculus. My focus has been on what it is about exchange-and specifically about market exchange as we normally conceptualize it - that is most significant when we carry the exchange paradigm into the arena of politics, as the Calculus sets itself to do. In this connection, I have contrasted the notion of exchange as a mechanism for mobilizing generalized gains-from-exchange with the notion of exchange as an instantiation of interactions that are voluntary and (therefore?) non-coercive.

One way of intruding this distinction into the Calculus analytics is in terms of a distinction we might draw between decision-making and external costs. It will be recalled that these costs are the primary ingredients in the calculus that produces the 'optimal collectivedecision-making rule'. Let us for the purposes of the exercise here take for granted: the definitions and constructions of these two types of costs; and the relations between these costs and different decision rules as set out in Chap. 6 and the various diagrams (1 through 6) contained in that chapter. Note that the derivation of the 'optimal' decision rule involves the simple addition of the two components: the point at which that sum is minimized is identified as 'optimal.' If this procedure seems, on its face, unexceptionable that is because, I want to suggest, we have implicitly adopted a "gains-from-exchange" perspective on the normative status of exchange.

Note specifically a difference between decision-making and external costs. Decisionmaking costs are ones that the agents who are party to the decision process voluntarily make. External costs by contrast are costs that are imposed on you involuntarily. Of course, sometimes you yourself will be able to impose such costs on others and that will compensate you

\footnotetext{
${ }^{12}$ Along lines represented in Buchanan (1975b) perhaps.
} 
somewhat for the instances in which you lose out. In that sense the net expected decisionmaking costs are some fraction of the total losses that each less-than-unanimously-approved decision imposes on someone. ${ }^{13}$ Now if the normative status of consent/voluntariness in transactions plays some independent role-if the "safe-guarding of the economic rights to which you are entitled under the existing property order" captures something of what we mean by 'non-coerciveness' and coercion is a prima facie bad-then external costs have a feature that decision-making costs do not. External costs might then bear some extra weight—and the 'optimal' decision-making rule would then be more inclusive (closer to unanimity).

Of course, one might respond-as any natural economist ${ }^{14}$ is perhaps prone to dothat the 'economic' approach to politics just embodies the application of homo economicus steadfastly and that homo economicus motivations allow no place for liberty/justice/antipathy-to-coercion, except as they bear on future wealth possibilities. Or one might respond that any preference the agent has for liberty/justice/antipathy-to-coercion can be treated as already embodied in the decision-making schedule; and that it is only insofar as constitutional contractors have a taste for such things that they deserve to figure in the calculus. Or, one who is attuned to the "broader norms of social interaction" might think that the quasivoluntariness of transactions has some independent normative value and that in any proper normative treatment, that aspect ought to be noted and brought to bear in its own right. In either of these latter two cases, the simple addition of decision-making and external costs as if they had identical status is inappropriate. In the Calculus, Buchanan seems to commit to the Tullockian view. However, on a Nozickean view of exchange in which it is the voluntariness of exchange that is normatively significant, that simple addition seems distinctly dubious. The general question that emerges here is this: What is it about "exchange" that the "politics-as-exchange" approach identifies as important? This seems to me to be a significant and relevant question — and one that lacks a simple or straightforward answer.

\section{References}

Buchanan, J. M. (1969). Cost and choice. Chicago: Markham Publishing Company.

Buchanan, J. M. (1975a). The limits of liberty. Chicago: University of Chicago Press.

Buchanan, J. M. (1975b). The political economy of the franchise in the welfare state. In R. Selden (Ed.), Capitalism and freedom: problems and prospects, Charlottesville: University of Virginia Press.

Buchanan, J. M. (1987). The qualities of a natural economist. In C. Rowley (Ed.), Democracy and public choice, Oxford: Basil Blackwell.

Buchanan, J. M., \& Brennan, G. (1985). The reason of rules: constitutional political economy. Cambridge: Cambridge University Press.

Brennan, G., \& Buchanan, J. M. (1988). Is public choice immoral? Virginia Law Review, 74, 179-189.

Buchanan, J. M., \& Tullock, G. (1962). The calculus of consent. Ann Arbor: University of Michigan Press.

Buchanan, J. M., \& Yoon, Y. J. (Eds.) (1994). The return to increasing returns. Ann Arbor: University of Michigan Press.

Lindahl, E. (1919/1958). Just taxation-a positive solution. In R. A. Musgrave \& A. T. Peacock (Eds.), Classics in the theory of public finance, London: MacMillan. 1958.

Smith, A. (1776/1981). The wealth of nations, Indianapolis: Liberty Classics.

Wicksell, K. (1896/1958). A new principle of just taxation. In R. A. Musgrave \& A. T. Peacock (Eds.), Classics in the theory of public finance, London: MacMillan. 1958.

\footnotetext{
${ }^{13}$ So in particular if imposing costs involuntarily is questionable, it will be so whether you are the imposer or the imposee. The fact that in a community of thieves you will sometimes be a beneficiary of theft and sometimes a victim does not mean that the amount of theft should be calculated in net terms if theft is independently dubious.

${ }^{14}$ Of whom, recall, Tullock is a recognizable prototype.
} 